\title{
COVID-19-induced granulomatosis with polyangiitis
}

\author{
Vijairam Selvaraj, ${ }^{1,2}$ Abdelmoniem Moustafa, ${ }^{1,2}$ Kwame Dapaah-Afriyie, ${ }^{1,2}$ \\ Mark P Birkenbach ${ }^{3}$
}

${ }^{1}$ Hospital Medicine, Miriam Hospital, Providence, Rhode Island, USA

Internal Medicine, Brown University Warren Alpert Medica School, Providence, Rhode Island, USA

${ }^{3}$ Pathology, Pathology and Laboratory Medicine, Brown University, Providence, Rhode Island, USA

Correspondence to

Dr Vijairam Selvaraj;

vijairam.selvaraj@lifespan.org

Accepted 9 March 2021

Check for updates

(c) BMJ Publishing Group Limited 2021. No commercial re-use. See rights and permissions. Published by BMJ.

To cite: Selvaraj $\mathrm{V}$

Moustafa A

Dapaah-Afriyie K, et al. BMJ

Case Rep 2021;14:e242142.

doi:10.1136/bcr-2021-

242142

\section{SUMMARY}

COVID-19 and granulomatosis with polyangiitis share many clinical and radiological features, making it challenging for clinicians to distinguish between the two. In this case report, we describe a patient who was diagnosed with COVID-19 in October 2020. One month later, she presented with persistent fatigue, shortness of breath and anaemia with worsening renal functions, found to have elevated antineutrophil cytoplasmic antibodies and antiproteinase 3 antibodies, and diagnosed with granulomatosis with polyangiitis.

\section{BACKGROUND}

Granulomatosis with polyangiitis (GPA) is a systemic disorder characterised by necrotising granulomatous vasculitis of small arteries and veins. Most patients present with respiratory symptoms such as cough, haemoptysis and dyspnoea. Renal involvement is only evident in 11\%-20\% at initial presentation, although glomerulonephritis develops in $77 \%-85 \%$ of the patients within the first 2 years of diagnosis. ${ }^{1}$ It may be challenging for clinicians to differentiate between GPA and COVID-19 as they share many clinical and radiological features.

\section{CASE PRESENTATION}

A 60-year-old woman with a history of dietcontrolled diabetes mellitus, allergic rhinitis, and a diagnosis of COVID-19 4 weeks ago, presented to the hospital for a second time with a persistent cough, fatigue and poor appetite. She had been discharged 2 weeks prior for chest pain and shortness of breath, felt to be secondary to COVID19-induced myopericarditis. She was treated with colchicine and ibuprofen, although she only took the medications for a few days and then was told to stop by her primary care provider due to a rise in her creatinine. Her creatinine was between 1.6 and $1.98 \mathrm{mg} / \mathrm{dL}$, from a baseline of $0.72 \mathrm{mg} / \mathrm{dL}$. Her home medications included lansoprazole and fluticasone. There is no family history of autoimmune disorders. She did not receive dexamethasone, tocilizumab or remdesivir for treatment of COVID-19 during her initial admission.

\section{INVESTIGATIONS}

Physical examination at the time of admission was only remarkable for conjunctival pallor. She was noted to have a temperature of 100.4 and haemoglobin of $65 \mathrm{~g} / \mathrm{L}$. Her $\mathrm{C}$ reactive protein was $180 \mathrm{mg} / \mathrm{L}$, and D-dimer was $2030 \mathrm{ng} / \mathrm{mL}$. She maintained adequate oxygen saturation on ambient air. CT scan of the chest done at the time of admission revealed ground-glass opacities (GGOs) in bilateral lungs. Iron studies revealed elevated ferritin and low iron. She received two units of packed red blood cells with improved haemoglobin up to $9.5 \mathrm{~g} /$ dL. SARS-CoV-2 test was negative. On day 3 of her hospitalisation, her creatinine increased up to $2.96 \mathrm{mg} / \mathrm{dL}$ from $2.65 \mathrm{mg} / \mathrm{dL}$ at the time of admission. Her urine analysis revealed gross haematuria and proteinuria. Rheumatological work-up showed elevated antineutrophil cytoplasmic antibody (c-ANCA) titres (1:320) and elevated proteinase 3 (PR3) antibodies (>8.0 antibody index). Her protein creatinine ratio was 2.0 , and microalbumin creatinine ratio was 636 . On day 5 , her creatinine peaked at $4.18 \mathrm{mg} / \mathrm{dL}$. A renal biopsy was performed that showed severe crescenteric and necrotising glomerulonephritis (figure 1) along with tubulointerstitial nephritis (figure 2), and a diagnosis of GPA was made.

Nephrology and rheumatology consultants recommended starting intravenous solumedrol $500 \mathrm{mg}$ daily along with rituximab that resulted in slight improvement in renal functions. On day 14 , she reported haemoptysis and required $15 \mathrm{~L} /$ min high-flow oxygen to maintain adequate oxygen saturation. CT scan of her chest revealed bilateral perihilar areas of dense lung consolidation, suggestive of diffuse alveolar haemorrhage. She was transferred to the intensive care unit for plasma exchange. Her hospital course was complicated by acute anaemia due to gastrointestinal haemorrhage along with cytomegalovirus colitis for which she was started on valganciclovir. A repeat CT scan showed worsening bibasilar pulmonary consolidation and GGOs.

\section{OUTCOME AND FOLLOW-UP}

Her respiratory status along with her creatinine slowly improved over the course of her hospitalisation. She was discharged home after 4 weeks on a gradual prednisone taper along with atovaquone for pneumocystis jiroveci pneumonia (PJP) prophylaxis. Her creatinine remained stable at $2.18 \mathrm{mg} / \mathrm{dL}$ at 1-month follow-up.

\section{DISCUSSION}

Diagnostic criteria for GPA consist of clinical evidence of disease in at least two of three areas (upper airways, lung and kidney), and biopsy results showing disease in at least one and preferably two of these organ systems. ${ }^{1}$ Given the high prevalence of lung involvement, a CT scan is commonly performed in GPA. Significant chest CT scan findings are GGOs, consolidation, masses or nodules, which may cavitate. ${ }^{2}$ These features are non-specific and can be seen in other conditions, including 


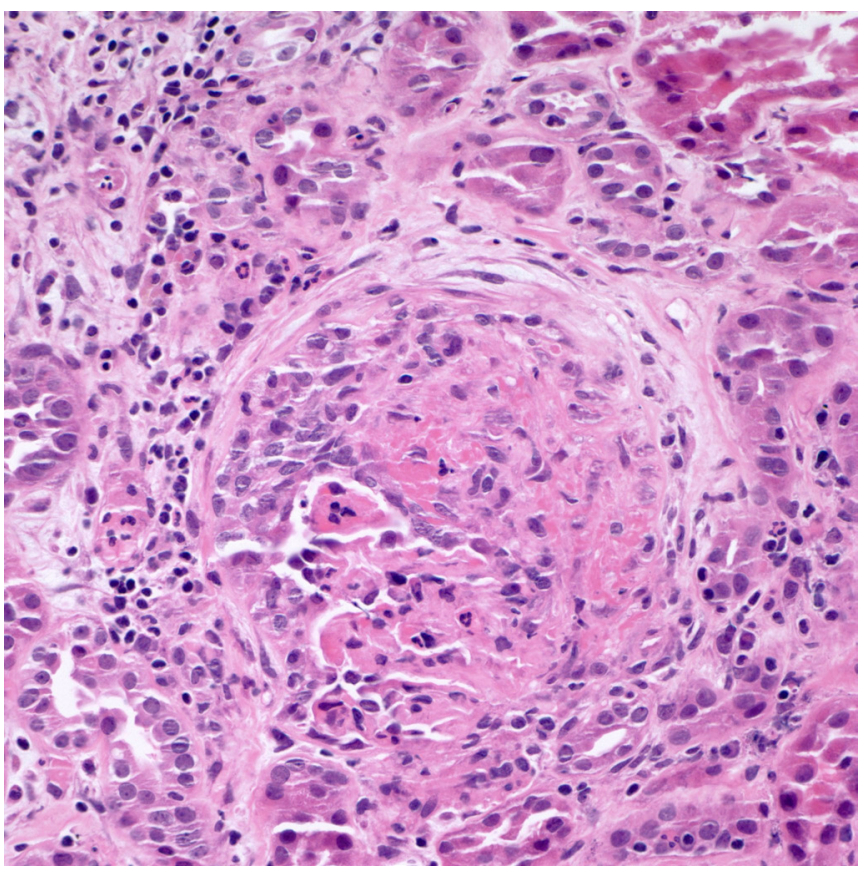

Figure 1 Glomerulus demonstrating segmental fibrinoid necrosis and epithelial crescent formation accompanied by interstitial oedema and intense inflammation. Tubular inflammation and epithelial injury are also noted (H\&E stain, 400x).

COVID-19 pneumonia, PJP and lupus pneumonitis. Lung haemorrhage, seen in the disease's active phase, may present as GGOs and consolidation in CT imaging. Patients with COVID-19 also sometimes present with acute kidney injury and haematuria due to rhabdomyolysis. ${ }^{3}$

As GPA and COVID-19 pneumonia share clinical and radiological features, diagnosis can be challenging. Clinicians are

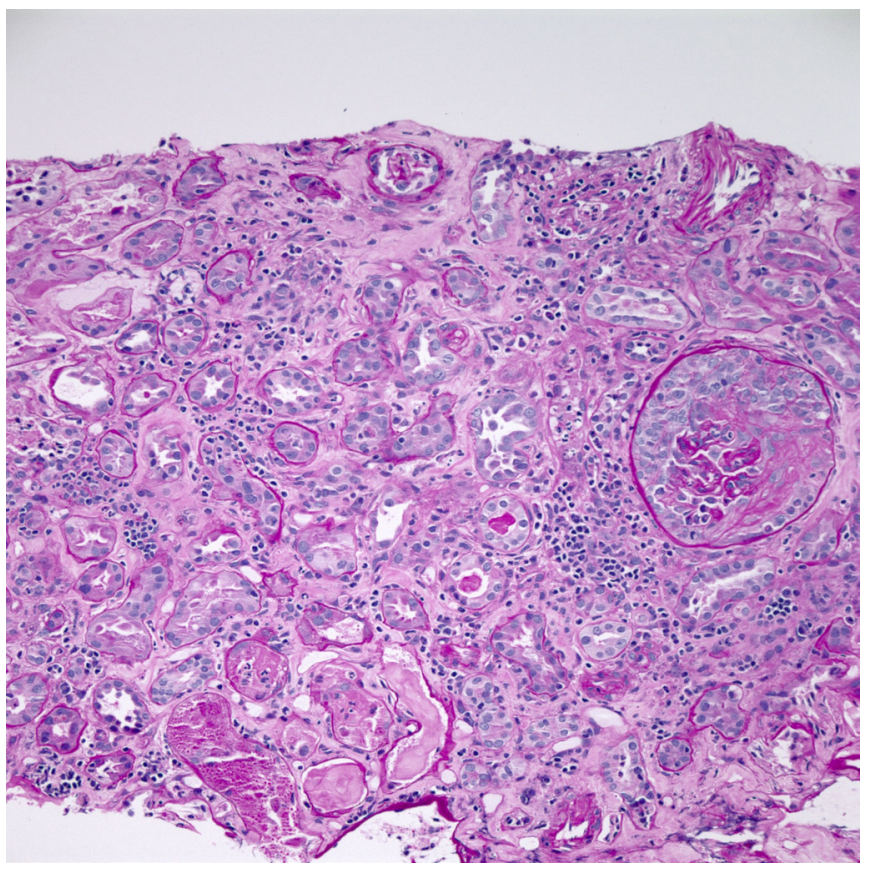

Figure 2 Fibroepithelial crescent with collapse of the underlying glomerular capillary tuft. Surrounding renal cortex demonstrates acute and chronic tubulointerstitial nephritis with severe tubular epithelial injury (PAS stain, 200x). blindsighted by COVID-19, often missing conditions such as GPA. ${ }^{4}$ Despite being in a pandemic, clinicians must have a broad differential diagnosis, especially when the clinical picture is not consistent with COVID-19. Our patient had normal oxygen saturation and downtrending inflammatory markers, yet her renal function continued to deteriorate with persistent haematuria and proteinuria. Features such as irregularly walled cavities, ANCA antibodies and proteinuria also help in differentiating GPA from COVID-19.

The mechanism is unclear. Many patients with GPA initially present with upper respiratory symptoms. SARS-CoV-2 has high affinity for ACE2 receptors in the respiratory tract and can also directly invade the endothelial cells to cause vasculitis. In addition, myeloperoxidase (MPO) and PR3 enzymes are present on neutrophils, and autoantibodies to these enzymes can lead to pauci-immune glomerulonephritis. There is also evidence that neutrophil extracellular traps (NETs) serve as a source of autoantigens presenting MPO and PR3 to the immune system. NETs have been noticed on kidney biopsy samples of patients with ANCA-associated vasculitis and could be involved in the pathogenesis. $^{5-7}$

The diagnosis of GPA is often overlooked and delayed due to a wide range of clinical presentations. It is extremely rare to develop GPA after COVID-19 infection. ${ }^{8}$ Another case report described a patient diagnosed with GPA with positive COVID-19 IgM and negative PCR test. ${ }^{9}$ However, in our case, GPA developed 4 weeks after true COVID-19 infection confirmed by positive SARS-CoV-2 PCR test. Treatment of GPA involves a multidisciplinary approach and usually includes corticosteroids, rituximab or cyclophosphamide. ${ }^{10}$

In conclusion, early diagnosis of GPA requires a high index of suspicion in all patients, especially in atypical presentation cases. This case report suggests association between COVID-19 infection and new-onset GPA. Prompt diagnosis and appropriate management of GPA in patients previously infected or coinfected with COVID-19 are essential to reduce morbidity and mortality.

\section{Learning points}

- Distinguishing between granulomatosis with polyangiitis (GPA) and COVID-19 is difficult given similarity in clinical and radiological features.

- Features such as irregularly walled cavities, antineutrophil cytoplasmic antibodies and proteinuria help in differentiating GPA from COVID-19.

- Physicians must have a high index of suspicion, especially in patients with atypical presentation to start immunosuppressive therapy.

\section{Twitter Vijairam Selvaraj @Vj235}

Contributors VS was involved in writing the manuscript and obtaining consent. $A M$ and $K D-A$ were involved in reviewing the manuscript and making critical edits. MPB was involved in reviewing, interpreting the pathology slides and providing the description of the images.

Funding The authors have not declared a specific grant for this research from any funding agency in the public, commercial or not-for-profit sectors.

Competing interests None declared.

Patient consent for publication Obtained.

Provenance and peer review Not commissioned; externally peer reviewed.

This article is made freely available for use in accordance with BMJ's website terms and conditions for the duration of the covid-19 pandemic or until otherwise determined by BMJ. You may use, download and print the article for any lawful, 
non-commercial purpose (including text and data mining) provided that all copyright notices and trade marks are retained.

\section{REFERENCES}

1 Fauci AS, Haynes BF, Katz P, et al. Wegener's granulomatosis: prospective clinical and therapeutic experience with 85 patients for 21 years. Ann Intern Med 1983;98:76-85

2 Lohrmann C, Uhl M, Kotter E, et al. Pulmonary manifestations of Wegener granulomatosis: CT findings in 57 patients and a review of the literature. Eur J Radiol 2005:53:471-7.

3 Ahmadian E, Hosseiniyan Khatibi SM, Razi Soofiyani S, et al. Covid-19 and kidney injury: pathophysiology and molecular mechanisms. Rev Med Virol 2020:e2176.

4 Shenavandeh S, Sefidbakht S, Iranpour P, et al. COVID-19 and granulomatosis with polyangiitis (GpA): a diagnostic challenge. Rheumatology 2020;59:2170-1.
5 Moeinzadeh F, Dezfouli M, Naimi A, et al. Newly diagnosed glomerulonephritis during COVID-19 infection undergoing immunosuppression therapy, a case report. Iran J Kidney Dis 2020;14:239-42.

6 Sharma P, Uppal NN, Wanchoo R, et al. COVID-19-Associated kidney injury: a case series of kidney biopsy findings. J Am Soc Nephrol 2020;31:1948-58.

7 Puelles VG, Lütgehetmann M, Lindenmeyer MT, et al. Multiorgan and renal tropism of SARS-CoV-2. N Engl J Med 2020;383:590-2.

8 Jalalzadeh M, Valencia-Manrique JC, Boma N, et al. Antineutrophil cytoplasmic antibody-associated glomerulonephritis in a case of scleroderma after recent diagnosis with COVID-19. Cureus 2021;13:e12485.

9 Tzouvelekis A, Karampitsakos T, Krompa A, et al. False positive COVID-19 antibody test in a case of granulomatosis with polyangiitis. Front Med 2020;7:399.

10 Langford CA. Update on the treatment of granulomatosis with polyangiitis (Wegener's). Curr Treat Options Cardiovasc Med 2012;14:164-76.

Copyright 2021 BMJ Publishing Group. All rights reserved. For permission to reuse any of this content visit https://www.bmj.com/company/products-services/rights-and-licensing/permissions/

BMJ Case Report Fellows may re-use this article for personal use and teaching without any further permission.

Become a Fellow of BMJ Case Reports today and you can:

- Submit as many cases as you like

Enjoy fast sympathetic peer review and rapid publication of accepted articles

- Access all the published articles

Re-use any of the published material for personal use and teaching without further permission

Customer Service

If you have any further queries about your subscription, please contact our customer services team on +44 (0) 2071111105 or via email at support@bmj.com.

Visit casereports.bmj.com for more articles like this and to become a Fellow 